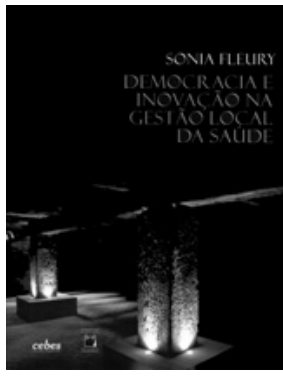

Paulo Henrique de Almeida Rodrigues ${ }^{1}$
1 Universidade do Estado do Rio de Janeiro (Uerj), Instituto de Medicina Social (IMS) - Rio de Janeiro (RJ), Brasil. Universidade Estácio de Sá (Unesa), Programa de Pós-Graduação em Saúde da Família - Rio de Janeiro (RJ), Brasil. Centro de Brasileiro de Estudos de Saúde (Cebes), Brasil. pharodrigues@gmail.com

\title{
FLEURY, S. Uma rica avaliação da construção da gestão democrática da saúde no nível local. Rio de Janeiro: Cebes: Editora Fiocruz, 2014.
}

É com prazer que recebi a incumbência de fazer esta resenha do livro 'Democracia e inovação na gestão local da saúde', de Sonia Fleury, militante, fundadora e ex-presidente do Cebes (2006-2009), em coautoria com Assis Mafort Ouverney, Felipe Barbosa Zani, Renato Cesar Möller e Thais Soares Kronenberg. O livro resulta de duas pesquisas desenvolvidas em 1996 e 2006, foi coeditado pelo Cebes e pela Editora Fiocruz e aborda um tema desafiador da reforma sanitária brasileira: o papel da gestão local da saúde e sua relação com a democratização das políticas públicas. Não foi sem dificuldades que fiz a resenha, afinal tinha de elaborar um texto que não fizesse feio perante o competente prefácio de Fernando Abrucio e perante a profundidade e extensão da obra. São ainda raras as pesquisas longitudinais, como esta que busca detectar a evolução da implantação do Sistema Único de Saúde (SUS). Esse é um dos grandes méritos do livro, que ao mesmo tempo explica uma limitação: como a segunda pesquisa teve de manter coerência com a primeira, para permitir a comparação, não pôde aprofundar certos temas sobre os quais a discussão avançou recentemente. Este é um caso típico, entretanto, em que os méritos são maiores do que os prejuízos.

Os dois eixos do livro são a 'democratização', pela via da municipalização, e a 'inovação' na gestão local da saúde. Temas presentes desde o início da formulação da reforma sanitária brasileira. Foi, afinal, em municípios que ocorreram algumas experiências inovadoras que contribuíram para a inspiração e para o desenvolvimento da reforma. Antes do SUS, pode-se recordar, entre outros: o Projeto Montes Claros, que inovou na estruturação da rede de saúde e na participação comunitária, ainda nos anos 1970 (ESCOREL, 1998); o Projeto Niterói, que inovou na atenção primária e na organização distrital dos serviços de saúde (MOYSES, 1989); além do Projeto Papucaia (Cachoeiras de Macacu), na incorporação do saber popular nas práticas de saúde (CESPP, 2015), ambos nos anos 1980. Deve-se registrar nessa linha, também: o Programa de Desenvolvimento de Comunidades Urbanas do Rio de Janeiro (1981-1986), talvez a primeira experiência brasileira com agentes comunitários de saúde, conduzida por Karen Giffin (RODRIGUES, 1988); a criação dos Núcleos de Atenção Psicossocial, em Santos, e do Centro de Atenção Psicossocial Prof. Luiz da Rocha Cerqueira, em São Paulo, por gestões petistas logo no início do SUS, que contribuíram para a reforma psiquiátrica em curso (LUZIO; L'ABBATE, 2006). Outros exemplos importantes são as experiências de Icapuí e Quixadá, nos anos 1980, também em gestões petistas, que inspiraram a criação dos Programas de Agentes Comunitários de Saúde do Estado do Ceará e Nacional de Agentes Comunitários de Saúde (LOTTA, 2006). Fico por aqui, assumindo o risco da omissão de importantes experiências.

O tema da municipalização da saúde foi caro e central desde relativamente cedo no movimento da reforma sanitária. O ideal da municipalização buscou inspiração no princípio da democratização das políticas públicas e não deixava de idealizar e simplificar a experiência da Ágora grega, e na menos 
falada, maior facilidade que lideranças do movimento sanitário tiveram inicialmente de penetrar na gestão da saúde pela via municipal. Afinal a primeira era bastante restrita, uma vez que dela só participavam os homens ricos, com mais de 26 anos, e foi efetivamente pela via municipal que diversos líderes da Reforma Sanitária estrearam na gestão do SUS. A própria pesquisa que originou o livro partiu "da hipótese de que a descentralização levaria à democratização da esfera local de governo" (2014, P. 18), que é o tema central do primeiro capítulo. $\mathrm{O}$ texto aponta o perigo que a ênfase recente dos estudos sobre "governança" tende a deslocar a discussão sobre as políticas públicas do âmbito político das relações entre o Estado e a sociedade e enxerga os cidadãos principalmente como consumidores. No capítulo, Sonia Fleury faz conclamação para a necessidade de se focar a discussão sobre as políticas públicas nas questões da democratização do Estado e da construção de cidadania emancipatória.

O segundo capítulo, 'A construção da municipalização da saúde: estratégias normativas', de Assis Monfort Ouverney, aborda os caminhos da municipalização do SUS, iniciados pela Lei Orgânica da Saúde (BRASIL, 1990), e que tanto entusiasmou o movimento sanitário. Tal entusiasmo pode ser medido pelo lema 'a municipalização é o caminho', da IX Conferência Nacional de Saúde (BRAsílIA, 1992), e por medidas tomadas pelos reformadores já no Ministério da Saúde, a partir de 1988. Foi o caso, principalmente, das Normas Operacionais Básicas (NOB) 01/93 (BRASIL, 1993) e 01/96 (BRASIL, 1996). Para melhor caracterizar o clima pró-municipalização vigente nos anos 1990, é importante lembrar que a NOB 01/93 tinha por inspiração o documento 'Descentralização das ações e serviços de saúde: a ousadia de cumprir e fazer cumprir a lei', aprovado pelo Conselho Nacional de Saúde, em abril de 1993.

O texto de Ouverney destaca a NOB 01/93 como o início efetivo da municipalização e mostra que ela não "estabeleceu qualquer estratégia específica da indução de arranjos regionalizados de serviços de saúde" (2014, P. 97), assim como a NOB 01/96 também revelava uma interpretação do "federalismo integrado de bases claramente municipalistas" (2014, P. 101), embora proponha os primeiros elementos de indução da regionalização - as Comissões Intergestores Bipartites (CIB) e a Programação Pactuada Integrada (PPI). Não aborda, entretanto, consequências da adoção entusiasmada e acrítica da municipalização pelo movimento sanitário, que deixou de considerar o papel do município na formação do Estado brasileiro. $\mathrm{O}$ afã municipalizador abstraiu, em primeiro lugar, que os governos locais são, desde os tempos coloniais, a base do poder da oligarquia agrária no Estado brasileiro e suas práticas patrimonialistas e do clientelistas (RODRIGUES, 2014). Tal abstração pode-se explicar, em parte, pela consciência um tanto difusa que o movimento tinha da frágil base de sustentação social da Reforma. Afinal, os trabalhadores haviam sido capturados nos anos 1970 pela miragem da saúde privada, fenômeno que ainda está à espera de elucidação pela crítica política e pela pesquisa acadêmica. $O$ frágil suporte social do SUS certamente facilitou a aceitação da aliança com o conservador movimento municipalista brasileiro (RODRIGUES, 2014).

O papel do município no Estado brasileiro é abordado parcialmente no capítulo quatro, de Fleury e Ouverney, ao tratar da renovação das elites locais da saúde - perfil dos secretários de municipais de saúde. O capítulo aponta dificuldades para a democratização do poder local, por conta das tradições do coronelismo, mandonismo e clientelismo que dificultam o "acesso dos cidadãos o interior aos benefícios do poder público" (2014, P. 204). A análise dos resultados de ampla gama de dados sugere que o perfil dos secretários estaria alinhado com a maior democratização do poder, entre outras coisas, em função da diversificação crescente do seu perfil, maior presença de "profissões qualificadas", maior participação das mulheres e "de 
grupos minoritários ou em desvantagem socioeconômica" (2014, P. 284). É pena que a pesquisa não tenha inquirido sobre os possíveis laços pessoais e familiares dos gestores com os proprietários rurais, detentores de grande parcela de poder nos menores municípios, nem com o setor privado de saúde, que disputa com o SUS pelo controle de recursos.

Os capítulos cinco e seis tratam da governança local no SUS e da modernização da gestão local. Os autores enxergam evidências de maior democratização da relação Estado e sociedade na gestão local da saúde, por conta da maior identificação dos atores com a mesma embora pouco, ainda, em relação à gestão orçamentária. Continuaria havendo, contudo, elevada influência do Ministério da Saúde sobre a agenda local do setor, o que indica uma limitação da descentralização política e administrativa. O capítulo sete apresenta conclusões otimistas sobre a oferta de serviços e inovações na gestão. Aponta a existência de diferentes padrões de inovação, predominando a média e baixa difusão desta, de insuficiente capacidade de identificação da demanda reprimida e dos mecanismos de organização da oferta nos menores municípios e que o "modelo de indução do centro para a periferia" (2014, P. 410) adotado pelo Ministério da Saúde pode estar contribuindo e inibindo a inovação na gestão e reduzindo a "autonomia dos municípios para pensar em soluções originais" (2014, P. 411). $O$ tom do texto é favorável à municipalização e avança pouco em relação à "regionalização e hierarquização da rede de serviços de saúde" (BRASIL, 1990), o segundo aspecto estabelecido pela Lei Orgânica da Saúde para a efetivação do princípio da "descentralização político-administrativa” (BRASIL, 1990).

Embora não seja analisado pela pesquisa, outro aspecto também abstraído pelo movimento sanitário ao abraçar a causa da municipalização é o fato de que $85 \%$ dos 5.565 municípios brasileiros têm menos de 50 mil habitantes, o que inviabiliza que contem com sistemas de saúde completos.
Ora, dizem os defensores da municipalização, tal problema pode ser corrigido pela regionalização do sistema, prevista na LOS. De fato, 12 anos da aprovação do SUS pela Constituição, tal objetivo passou a ser perseguido, embora sem muito sucesso, por diversas medidas do Ministério da Saúde, como as Normas Operacionais de Assistência à Saúde (Noas), de 2001 e 2002, o Pacto pela Saúde, de 2006, e mais recentemente, pelo Decreto Presidencial n. ${ }^{\circ}$ 7.058, de 2011. São várias, entretanto, as dificuldades para o sucesso de tais iniciativas.

A mais imediata e visível diz respeito ao problema da gestão cooperativa, através dos frágeis, frouxos e instáveis 'condomínios regionais' que constituem as nossas regiões de saúde. Elas são compostas por um número geralmente excessivo de municípios autônomos entre si e dirigidos por forças e interesses políticos distintos. Cada município controla separadamente seus próprios recursos - unidades de saúde, profissionais e recursos financeiros. Nenhum outro sistema universal de saúde existente no mundo aventurou-se a montar uma gestão fragmentada desse tipo. Todos contam com algum tipo de autoridade sanitária regional que controla o conjunto dos recursos da rede de ações e serviços de saúde, inclusive os financeiros. Algumas regiões de saúde brasileiras são tão grandes que tornam sua governabilidade altamente improvável, como é o caso, entre muitos, da macrorregião de saúde de Belo Horizonte, composta por 102 municípios que somam mais de seis milhões de habitantes (SANTOS, 2013).

Ligado a esse fator, houve abstração por parte do movimento sanitário do papel dos municípios no sistema político eleitoral brasileiro. Eles constituem a base desse sistema, cujas circunscrições eleitorais correspondem ao território dos estados, uma vez que não contamos com nenhum tipo de distrito eleitoral. Circunscrições eleitorais tão grandes obrigam candidatos aos cargos eletivos estaduais e federais a buscar votos 
em muitos municípios, espalhados por territórios maiores do que muitos países. As campanhas eleitorais no Brasil ficam caras demais por esta razão e dependem de acordos e compromissos eleitorais em diversos municípios, onde a saúde costuma ser importante moeda de troca. Ainda há pouco estudo e baixa consciência sobre como isso torna ainda mais complexa a pretendida e necessária regionalização do nosso sistema público de saúde.

O sistema político-eleitoral democrático é de natureza competitiva e não cooperativa, o que contradiz o falso ideal do 'federalismo cooperativo', para o qual muitos apelam para resolver as consequências da fragmentação municipalista do SUS. As autoridades políticas municipais vizinhas tendem mais a competir politicamente do que a cooperar entre si para um funcionamento mais integrado da rede de serviços. São incentivadas a isso pelo sistema político-eleitoral, porque quando prefeitos, vereadores e mesmo secretários de saúde se candidatam a cargos eletivos nas esferas estadual e federal, precisam angariar votos em diversos municípios dos respectivos estados, particularmente nos vizinhos imediatos, onde tendem a ser mais conhecidos. Uma cooperação muito estreita que fortaleça serviços de saúde localizados em outros municípios costuma ser vista como uma forma de 'colocar a azeitona na empada dos outros'.

Alguns dos aspectos acima apontados vêm sendo crescentemente reconhecidos pelo movimento sanitário e constituem a munição tanto para preocupações críticas com os rumos da municipalização como para as levantadas por importantes defensores da reforma sanitária, como fizeram os sanitaristas e militantes do Cebes Jairnilson Silva Paim, em artigo publicado em 1992, e Gastão Wagner Souza Campos (SANTOS; CAMPOS, 2014) ao propor a transformação do SUS em uma autarquia pública, organizada a partir das regiões de saúde.

\section{Referências}

BRASIL. Presidência da República. Lei nº. 8.080, de 19 de setembro de 1990. Dispõe sobre as condições para a promoção, proteção e recuperação da saúde, a organização e o funcionamento dos serviços correspondentes e dá outras providências. Diário Oficial [da] União. Brasília, DF, 19 set. 1990. Disponível em: <http://www. planalto.gov.br/ccivil_03/Leis/L8080.htm>. Acesso em: 2 nov. 2015.

Ministério da Saúde. Portaria GM/MS nº. 545, de 20 de maio de 1993. Estabelece normas e procedimentos reguladores do processo de descentralização da gestão das ações e serviços de saúde, através da Norma Operacional Básica - SUS 01/93. 1993. Diário Oficial [da] União. Brasília, DF, 20 maio 1993. Disponível em: <http://bvsms.saude.gov.br/bvs/saudelegis/gm/1993/ prt0545_20_05_1993.html>. Acesso em: 2 nov. 2015.

Portaria GM/MS nº. 2.203, de 5 de novembro de 1996. Redefine o modelo de gestão do Sistema Único de Saúde, constituindo, por conseguinte, instrumento imprescindível à viabilização da atenção integral à saúde da população e ao disciplinamento das relações entre as três esferas de gestão do Sistema. Diário Oficial [da] União. Brasília, DF, 05 nov. 1996. Disponível em: <http://bvsms.saude.gov.br/bvs/saudelegis/gm/1996/ prt2203_05_11_1996.html>. Acesso em: 2 nov. 2015.

CENTRO DE ESTUDOS DE SAÚDE DO PROJETO PAPUCAIA (CESPP). Quem somos. Disponível em: $<$ http://www.projetopapucaia.org/\#!about_us/csgz>. Acesso em: 2 nov. 2015.

ESCOREL, S. Reviravolta na Saúde: origem e articulação do movimento sanitário. Rio de Janeiro: Editora Fiocruz, 1998.

FLEURY. S. Uma rica avaliação da construção da gestão democrática da saúde no nível local. Rio de Janeiro: Cebes: Editora Fiocruz, 2014.

LOTTA, G. S. Saber e poder: agentes comunitários de saúde aproximando saberes locais e políticas públicas. 170 f. 2006. Dissertação (Mestrado em Administração 
Pública) - Escola de Administração de Empresas de São Paulo, Fundação Getúlio Vargas, São Paulo, 2006.

LUZIO, C. A.; L'ABBATE, S. A reforma psiquiátrica brasileira: aspectos históricos e técnico-assistenciais das experiências de São Paulo, Santos e Campinas. Interface, Botucatu, v. 10, n. 20, p. 281-298, 2006.

MOYSES, N. M. N. Projeto Niterói: uma tentativa de recuperaçao da história recente. Rev. Adm. Públ., Rio de Janeiro, v. 23, n. 1, p. 46-63, jan. 1989.

PAIM, J. S. A Reforma Sanitária e a municipalização. Saúde e Sociedade, São Paulo, v. 1, n. 2, p. 29-47, 1992.

RODRIGUES, P. H. A. Extensão dos serviços públicos às comunidades de baixa renda no município do Rio de Janeiro. Rio de Janeiro: Ibam/Unicef, 1988.
Desafios políticos para a consolidação do Sistema Único de Saúde: uma abordagem histórica. História, Ciências, Saúde - Manguinhos, Rio de Janeiro, v. 21, n. 1 , p. $37-59,2014$

SANTOS, D. L. Política, saúde da família e acesso a serviços de média e alta complexidade: o caso de Rio do Prado. 107 f. 2013. Dissertação (Mestrado em Saúde da Família) - Universidade Estácio de Sá, Rio de Janeiro, 2013.

SANTOS, L.; CAMPOS, G. W. S. SUS Brasil: a região de saúde como caminho. Campinas: Instituto de Direito Sanitário Aplicado, 2014. Disponível em: <http:// www.idisa.org.br/img/File/regi\%C3\%A3o\%20de\%20 saude\%20lenir\%20e\%20gast\%C3\%A3o\%20v_\%20 4\%20(1).pdf>. Acesso em: 8 dez. 2015. 